\section{BENIGN PROSTATIC \\ HYPERPLASIA: IS IT A GROWING PUBLIC HEALTH CONCERN FOR INDIA?}

Sir,

$\mathrm{BPH}$ is the most common urological problem of ageing men, manifested as severe obstruction in urinary flow with discomfort and pain. BPH is a complex disease from the etiological and pathogenesis point of view. ${ }^{[1]} \mathrm{A}$ recent AUA guideline (2003) suggests an increase in the incidence of BPH worldwide and predicts by the age of 60 years, more than $50 \%$ of men will have microscopic evidence of the disease and by the age of 85 years, as many as $90 \%$ of men will be affected. ${ }^{[2]}$ Worldwide investigations for incidence of BPH are scanty and at times difficult to compare due to uneven definition of BPH based on different clinical parameters. There is also great geographical disparity in prevalence and degree of severity of symptoms of $\mathrm{BPH}$. Benign enlargement of the prostate gland is reported to be most common in blacks, Caucasians, and Jews, but less frequent in males from the Far East.

Asian, particularly vegetarian, men consume low-fat, high-fiber diets rich in weak dietary phytoestrogens, which have been proposed as chemopreventive agents. But the very few studies conducted on BPH patients from India suggest $\mathrm{BPH}$ as the most common pathological condition with an incidence of $92.97 \%(n=185)$ ${ }^{[3]}$ and $\left(93.3 \%(n=200) .{ }^{[4]}\right.$ Though not well performed epidemiological investigations, these data along with clinicians' practical evidence indicate substantial need for a survey of the incidence of $\mathrm{BPH}$ in India. Interestingly, the
Prime Minister of India was reported in the 16 September 2007 issue of The Times of India to have undergone surgical treatment for benign enlargement of the prostate gland at the All India Institute of Medical Sciences. However, the actual current incidence of BPH will require valid scientific evidence from pooled data, and India as a whole lacks a large-scale screening database of patients diagnosed for any prostatic disease.

The recent increase in the $\mathrm{BPH}$ rate in several industrialized countries should inspire Indian urologists to more elaborate effort to investigate symptoms and risk factors of $\mathrm{BPH}$. Further, public health perspective research with factual data collected through national and regional centers to assess future trends in $\mathrm{BPH}$ incidence rates and defining ethnic characteristics, as also case-control studies, must be strongly encouraged to identify risk factors for the Indian population.

HEMANT KUMAR BID, RITURAJ KONWAR, VISHWAJEET SINGH

Endocrinology Division, Central Drug Research Institute, Lucknow, ${ }^{1}$ Chatrapati Sahuji Maharaj Medical University (CSMMU), Lucknow, India Correspondence:
Dr. Vishwajeet Singh,
Department of Urology,
Chatrapati Sahuji Maharaj Medical University (CSMMU),
Lucknow-226003, India. Correspondence:
Dr. Vishwajeet Singh,
Department of Urology,
Chatrapati Sahuji Maharaj Medical University (CSMMU),
Lucknow-226003, India. E-mail: viswajeet@sifymail.com

\section{REFERENCES}

1. Konwar R, Chattopadhyay N, Bid HK. Genetic polymorphism and pathogenesis of benign prostatic hyperplasia. BJI Int 2008;102: 536-44.

2. AUA Practice Guidelines Committee. AUA guideline on management of benign prostatic hyperplasia, Chapter 1: Diagnosis and treatment.
J Urol 2003:170:530-47.

3. Mittal BV, Amin MB, Kinare SG. Spectrum of histological lesions in 185 consecutive prostatic specimens. J Postgrad Med 1989;35:157-61.

4. Mathur SK, Gupta S, Marwah N, Narula A, Singh S, Arora B. Significance of mucin stain in differentiating benign and malignant lesions of prostate. Indian J Pathol Microbiol 2003;46:593-5 